\title{
Revisão sistemática sobre a presença de Núcleos de Acessibilidade na Educação Superior EaD - 2005 a 2018
}

\author{
Systematic review on the presence of Accessibility Nucleus in Higher \\ Education EaD - 2005 to 2018
}

Revisión sistemática sobre la presencia de Núcleos de Accesibilidad en la Educación Superior EaD - 2005 a 2018

\author{
* Renata Andrea Fernandes Fantacini \\ Professora doutora na Claretiano, Batatais, São Paulo, Brasil. \\ refantacini@hotmail.com - http://orcid.org/0000-0001-6149-7987 \\ ** Maria Amelia Almeida \\ Professora doutora na Universidade Federal de São Carlos, São Carlos, São Paulo, Brasil. \\ ameliana@terra.com.br
}

Recebido em 01 de outubro de 2018

Aprovado em 08 de abril de 2019

Publicado em 12 de setembro de 2019

\section{RESUMO}

A inclusão na Educação Superior vem ocupando crescente espaço nos debates educacionais nacionais e remetem à trajetória da democratização do ensino, mas percebese ainda certa fragilidade no que se refere às diretrizes, apesar da existência de um número expressivo de legislações nessa área específica. Este estudo objetivou apresentar uma revisão sistemática de Teses e Dissertações defendidas no Brasil sobre a presença de Núcleos de Acessibilidade na Educação Superior EaD. A metodologia utilizada foi a revisão sistemática de literatura. A busca das produções neste formato foi realizada na Biblioteca Digital Brasileira de Teses e Dissertações e no Banco de Teses e Dissertações da Capes/MEC, que abarca publicações disponíveis na Plataforma Sucupira no período de 2005 a 2018. Dessa forma, foram encontrados 39 estudos. As pesquisas sobre inclusão na Educação Superior tiveram maior ênfase a partir do ano de 2005, porém, somente a partir de 2014, que iniciou a presença do descritor núcleo de acessibilidade na educação superior. Nesse sentido, das teses e dissertações defendidas no Brasil até 2018, apenas um estudo de revisão teórica sobre inclusão na Educação Superior; outro estudo, de intervenção para a inclusão de estudantes com deficiência intelectual na Educação Superior; e somente um estudo, que trata da implementação de Núcleos de Acessibilidade na Educação Superior de uma IES privada, na modalidade de Educação a Distância. Concluiu-se que, por se tratar de uma área ainda pouco explorada no panorama nacional, outras pesquisas acerca dos Núcleos de Acessibilidade na Educação Superior EaD sejam realizadas.

Palavras-chave: Educação Especial; Educação Superior; Núcleo de Acessibilidade. 


\section{ABSTRACT}

Inclusion in Higher Education has been growing in the national educational debates and is reminiscent of the democratization of education, but there is still a certain weakness in the guidelines, despite the existence of a significant number of legislation in this specific area. This study aimed to present a systematic review of Theses and Dissertations defended in Brazil on the presence of Accessibility Nucleus in Higher Education EaD. The methodology used was the systematic review of the literature. The search for the productions in this format was carried out in the Brazilian Digital Library of Theses and Dissertations and in the Bank of Thesis and Dissertations of Capes / MEC, which covers publications available in the Sucupira Platform from 2005 to 2018. Thus, 39 studies were found. Research on Inclusion in Higher Education was more emphasized as of 2005, but only after 2014, which began the presence of the core descriptor of accessibility in higher education. In this sense, of the theses and dissertations, defended in Brazil until 2018, only a theoretical review study on inclusion in Higher Education; another study, of intervention for the inclusion of students with intellectual disabilities in Higher Education; and only one study, which deals with the implementation of Accessibility Nucleus in Higher Education of a private $\mathrm{HEl}$, in the form of Distance Education. It was concluded that, because it is an area still little explored in the national panorama, other researches about the Accessibility Nucleuses in Higher Education EaD are carried out.

Keywords: Special education; College education; Accessibility Nucleus.

\section{RESUMEN}

La inclusión en la Educación Superior viene ocupando un creciente espacio en los debates educativos nacionales y remiten a la trayectoria de la democratización de la enseñanza, pero se percibe aún cierta fragilidad en lo que se refiere a las directrices, a pesar de la existencia de un número expresivo de legislaciones en esa área específica. Este estudio objetivó presentar una revisión sistemática de Tesis y Disertaciones defendidas en Brasil sobre la presencia de Núcleos de Accesibilidad en la Educación Superior EaD. La metodología utilizada fue la revisión sistemática de literatura. La búsqueda de las producciones en este formato fue realizada en la Biblioteca Digital Brasileña de Tesis y Disertaciones y en el Banco de Tesis y Disertaciones de la Capes / MEC, que abarca publicaciones disponibles en la Plataforma Sucupira en el período de 2005 a 2018. De esa forma, se encontraron 39 estudios. Las investigaciones sobre inclusión en la Educación Superior tuvieron mayor énfasis a partir del año 2005, pero sólo a partir de 2014, que inició la presencia del descriptor núcleo de accesibilidad en la educación superior. En ese sentido, de las tesis y disertaciones, defendidas en Brasil hasta 2018, sólo un estudio de revisión teórica sobre inclusión en la Educación Superior; otro estudio, de intervención para la inclusión de estudiantes con discapacidad intelectual en la Educación Superior; y sólo un estudio, que trata de la implementación de Núcleos de Accesibilidad en la Educación Superior de una IES privada, en la modalidad de Educación a Distancia. Se concluyó que, 
por tratarse de un área aún poco explorada en el panorama nacional, otras investigaciones sobre los Núcleos de Accesibilidad en la Educación Superior EaD sean realizadas.

Palabras-clave: Educación Especial; Educación universitária; Núcleo de Accesibilidad.

\section{Introdução}

Em 1996, o Ministério da Educação e Cultura - MEC organizou um primeiro documento denominado Aviso Curricular no 277, direcionado aos reitores de instituições de Educação Superior - IES, solicitando a execução de uma política educacional direcionada e adequada aos portadores de necessidades especiais ${ }^{1}$, e thes requeriam que fossem dadas oportunidades de acesso e inclusão na Educação Superior (BRASIL, 1996).

Já em 2005, as IES federais concorreram a recursos para a estruturação de Núcleo de Acessibilidade (NA) por meio dos editais, do Programa Acessibilidade ao Ensino Superior - Incluir em parceria com a Secretaria de Educação Superior, com o objetivo de promover a acessibilidade nas instituições públicas de Educação Superior. Este programa tem como proposta garantir condições de acesso e participação aos estudantes com deficiência no contexto da Educação Superior, propondo a estruturação de um NA no contexto da Educação Superior. Sendo apoiados pelo MEC, de 2005 a 2012, 300 projetos de criação e consolidação de Núcleos de Acessibilidade em Instituições Federais de Ensino Superior (IFES).

Com a Política Nacional de Educação Especial na Perspectiva da Educação Inclusiva (BRASIL, 2008) que define a Educação Especial como modalidade transversal a todos os níveis, etapas e modalidades, enfatizou, ainda, a necessidade de promover a inclusão e o fortalecimento das políticas de acessibilidade inclusive nas instituições de educação superior. Embora considerada uma conquista, percebe-se ainda certa fragilidade no texto publicado no que se refere às diretrizes para a inclusão na Educação Superior, apesar da existência de um número expressivo de Leis, Decretos, Portarias e Aviso Curricular nessa área específica, voltadas para a inclusão na Educação Superior.

O Decreto oㅜ 7.611/2011 (BRASIL, 2011a) aponta para a estruturação de Núcleos de Acessibilidade na Educação Superior, fazendo menção às IFES, permanecendo, no entanto, fragilidades quanto à Inclusão na Educação Superior, visto que, no mesmo ano em que esse decreto entrou em vigor, o Censo da Educação Superior registrou um número

\footnotetext{
1 Termo utilizado na época, estando de acordo com a Política Nacional de Educação Especial de 1994.
} 
crescente de matrículas de estudantes PAEE na Educação Superior, muito maior nas IES privadas, em relação às IES públicas.

O Programa Incluir (BRASIL, 2013a), propõe em seu Documento Orientador, que a partir de 2012, os Núcleos de Acessibilidade das IFES passem a se estruturarem com base nos seguintes eixos: a) infraestrutura; b) Currículo, comunicação e informação; c) Programas de extensão; d) Programas de pesquisa. No mesmo ano, foi elaborado o documento Referencial de Qualidade para o Ensino Superior a Distância (BRASIL, 2007), que prevê algo mais específico para a inclusão na educação superior.

Somente a partir dos Referenciais de Acessibilidade na Educação Superior e a Avaliação In Loco do Sistema Nacional de Avaliação da Educação Superior (Sinaes) (BRASIL, 2013b), é que passa a ser oficialmente solicitado que as instituições de Educação Superior (públicas e privadas) a organização, implantação e implementação de Núcleos de Acessibilidade para o público-alvo da Educação Especial (BRASIL, 2013b).

Há ainda uma última versão atualizada do Instrumento de Avaliação de Cursos de Graduação Presencial e a Distância (BRASIL, 2016) que traz a preocupação com as condições de acesso e permanências para os estudantes PAEE na Educação Superior. Percebe-se que as Políticas de Educação Especial na Perspectiva da Educação Inclusiva para a Educação Superior encontram-se interligadas com as demais políticas voltadas para a inclusão.

Em 2016, entrou em vigor a Lei oㅜ 13.146, de 6 de julho de 2015 (BRASIL, 2015), mais conhecida como Lei Brasileira de Inclusão (LBI). Referente à Educação Superior, traz em seu Artigo 30 as diretrizes em relação aos processos seletivos para ingresso e permanência nos cursos disponibilizados pelas IES, públicas e privadas, de educação profissional e tecnológica.

Em 2017, foi sancionada a Lei oㅜ 13.409, de 28 de dezembro de 2016, regulamentada pelo Decreto ํㅜ 9.034, de 20 de abril de 2017, que alterou a Lei no 12.711, de 29 de agosto de 2012, para dispor sobre a reserva de vagas para pessoas com deficiência nos cursos técnicos de nível médio e superior das instituições federais de ensino, Denominada Lei de Cotas para as pessoas com deficiências (BRASIL, 2017; 2016; 2012).

Em termos de avanços legais, visando a garantia de acesso do público-alvo da Educação Especial na Educação Superior, percebe-se que, até o presente momento, em consequência da evolução do desenvolvimento inclusivo da Educação Básica, o conjunto 
de ações governamentais tem ampliado o acesso desse público na Educação Superior. Nesta direção, como se encontram as produções científicas (dissertações e teses) acerca da presença dos Núcleos de Acessibilidade no Ensino Superior EaD?

Isso posto, o objetivo desta pesquisa é apresentar uma revisão sistemática de estudos de dissertações e teses produzidas entre os anos 2005 e 2018 que colaboram para o conhecimento da produção científica encontrada no Brasil que trata a respeito de Núcleos de Acessibilidade no Ensino Superior para Educação a Distância (EaD).

\section{Método}

A metodologia utilizada foi a revisão sistemática (SAMPIERI; COLLADO; LÚCIO, 2013) de produções científicas (teses e dissertações). A busca das produções neste formato foi realizada na Biblioteca Digital Brasileira de Teses e Dissertações (BDTD) e no Banco de Teses e Dissertações da Capes/MEC, que abarca publicações disponíveis na Plataforma Sucupira no período de 2005 a 2018.

Optou-se por estudos completos, de Programas de Pós-graduação (Stricto Sensu) em Educação, Educação Especial e Psicologia, desse período, visto que 2005 é considerado um marco para a criação de Núcleos de Acessibilidade visando a Inclusão na Educação Superior.

Primordial notabilizar que primeiramente buscou-se pelo descritor "núcleo de acessibilidade em EaD", pelo qual não houve porção expressiva. Por essa razão uma nova busca foi realizada com os descritores "inclusão no ensino superior EaD" e "núcleos de acessibilidade".

\section{Resultados}

Após a leitura, foram selecionados 39 estudos, que atendiam o objetivo deste estudo, sendo 26 dissertações (mestrado) e 13 teses (doutorado). Considerando a carência dos estudos relacionados à temática sobre núcleo de acessibilidade na educação superior EaD, priorizou-se a apresentação descritiva de dissertações e teses, sendo identificadas e organizadas a partir do agrupamento das seguintes categorias: 1) Estudos sobre inclusão na Educação Superior em IES realizados em estados do país e em nível nacional; 2) Estudos sobre a inclusão na Educação Superior que tiveram como foco: docentes, funcionários, estudantes; 3) Estudos sobre avaliação de satisfação de estudantes PAEE em relação a inclusão na Educação Superior; 4) Estudo sobre a inclusão na Educação 
Superior de revisão teórica; 5) Estudo de intervenção para inclusão de estudantes com Deficiência Intelectual na Educação Superior; e 6) Estudo sobre Ações do Núcleo de Acessibilidade na EAD em Instituição de Educação Superior Privada. Conforme Quadro 2.

Quadro 1 - Categorias encontradas nas produções selecionadas.

\begin{tabular}{|c|c|c|c|}
\hline $\mathbf{N}$ & $\begin{array}{l}\text { Categorias } \\
\text { Encontradas }\end{array}$ & $\begin{array}{c}\text { Quantidade de } \\
\text { Teses e } \\
\text { Dissertações }\end{array}$ & Estudos \\
\hline 1 & $\begin{array}{l}\text { Estudos sobre inclusão } \\
\text { na Educação Superior } \\
\text { em IES realizado em } \\
\text { vários estados do país } \\
\text { e em nível Nacional. }\end{array}$ & $\begin{array}{c}27 \\
\text { (19 Dissertações e } \\
\text { 8 Teses) }\end{array}$ & $\begin{array}{l}2 \text { Inclusão do Surdo (ANSAY, 2009; } \\
\text { SILVA. 2017). } \\
3 \text { Inclusão de Deficientes Visuais } \\
\text { (FORTES, 2005; RAPOSO, 2006; } \\
\text { FERREIRA, 2010). } \\
11 \text { Inclusão em vários estados do país } \\
\text { (SASAZAWA, 2005; CHAHINI, 2006; } \\
\text { PELLEGRINI, 2006; PERINI, 2006; } \\
\text { DREZZA. 2007; ALCOBA, 2008; VIANA } \\
\text { (2010); BORGES, 2001; GUIMARÃES, } \\
\text { 2011, OLIVERIA, 2011; PIZA, 2011). } \\
3 \text { Políticas Públicas (REIS, 2010; } \\
\text { MIRANDA, 2014; SILVEIRA, 2015). } \\
5 \text { Acessibilidade (RAMALHO, 2012; } \\
\text { SANTOS, 2012; CASTILHO, 2012; } \\
\text { SARAIVA, 2015 e SANTANA, 2016). } \\
3 \text { Inclusão na Educação Superior em } \\
\text { nível Nacional (SOUZA, 2010; CASTRO, } \\
\text { 2011; CIANTELLI, 2015). }\end{array}$ \\
\hline 2 & $\begin{array}{l}\text { Estudos sobre inclusão } \\
\text { na Educação Superior } \\
\text { que tiveram como foco: } \\
\text { docente, funcionários e } \\
\text { estudantes. }\end{array}$ & $\begin{array}{c}7 \\
\text { (5 Dissertações e } \\
2 \text { Teses) }\end{array}$ & $\begin{array}{l}5 \text { Ponto de vista dos docentes (SANTOS, } \\
\text { 2009; SOUSA, 2009; ALBINO, 2010; } \\
\text { CHAHINI, } 2010 \text { e NOGUEIRA, 2010). } \\
2 \text { Atitudes sociais e opiniões (CHAHINI, } \\
\text { 2010; ROSSETTO, 2010; SHIMITE, } \\
\text { 2017). }\end{array}$ \\
\hline 3 & $\begin{array}{lr}\text { Estudos } & \text { sobre } \\
\text { Avaliação } & \text { de } \\
\text { Satisfação } & \text { de } \\
\text { Estudantes } & \text { PAEE em } \\
\text { relação a inclusão na } \\
\text { Educacão Superior. }\end{array}$ & $\begin{array}{c}2 \\
\text { (2 Teses) }\end{array}$ & $\begin{array}{l}2 \text { Avaliação de Satisfação e Atitudes } \\
\text { (GUERREIRO, 2011; CORRÊA, 2014). }\end{array}$ \\
\hline 4 & $\begin{array}{l}\text { Estudos sobre inclusão } \\
\text { na Educação Superior } \\
\text { de revisão teórica. }\end{array}$ & $\begin{array}{c}1 \\
\text { (Dissertação) }\end{array}$ & Urban (2016). \\
\hline 5 & $\begin{array}{l}\text { Estudo de intervenção } \\
\text { para inclusão de } \\
\text { estudantes com } \\
\text { Deficiência na } \\
\text { Educação Superior. }\end{array}$ & $\begin{array}{c}1 \\
\text { (Tese) }\end{array}$ & Lopes (2016). \\
\hline 6 & $\begin{array}{l}\text { Estudo sobre Ações do } \\
\text { Núcleo de } \\
\text { Acessibilidade na EAD } \\
\text { em Instituição de } \\
\text { Educação Superior } \\
\text { Privada }\end{array}$ & $\begin{array}{c}1 \\
(\mathrm{TESE})\end{array}$ & Fantacini (2017). \\
\hline
\end{tabular}

Fonte: Elaboração própria. 


\section{Estudos sobre inclusão na Educação Superior em IES realizados em estados do país} e em nível nacional

Referente a esta categoria, foram identificados 27 estudos sobre a Inclusão na Educação Superior em IES de vários estados do país, sendo 19 Dissertações (Mestrado) e 8 Teses (Doutorado), descritos brevemente a seguir.

Encontrou-se dois estudos voltados para a inclusão de estudantes com Surdez, sendo um de Ansay (2009), que apresentou como dissertação de mestrado, pelo Programa de Pós-graduação em Educação pela Universidade Federal do Paraná - UFPR, o estudo intitulado A trajetória escolar de estudantes surdos e a sua relação com a inclusão no ensino superior. O estudo objetivou investigar a trajetória educacional de nove estudantes surdos inseridos nas universidades de Curitiba-PR no ano de 2007, foram constatados possibilidades e desafios, ressaltando a importância dos núcleos de apoio e a necessidade dos serviços de apoio nas universidades, considerando-os como um caminho para práticas pedagógicas mais eficazes. Outro estudo foi de Silva (2017) que apresentou a dissertação intitulada como O processo de inclusão: objetivação e ancoragem do primeiro aluno surdo numa instituição de ensino superior. O presente estudo objetivou analisar como o modelo atual das políticas públicas voltadas para a educação do aluno surdo se concretiza nas representações sociais dos professores que lecionaram em uma Instituição do Ensino Superior (IES) do interior de Goiás no ano de 2016. Os resultados demonstraram que não houve um processo de inclusão e sim de integração na IES.

Outros três estudos encontrados são voltados para a inclusão de estudantes com Deficiência Visual, sendo o primeiro de Fortes (2005), apresentado no Programa de Pósgraduação em Educação da Universidade Federal do Rio Grande do Norte - UFRN, com a dissertação intitulada $A$ inclusão da pessoa com deficiência visual na UFRN: a percepção dos acadêmicos. Com o objetivo de analisar como vinha acontecendo a inclusão de estudantes com deficiência visual em três cursos da UFRN; o segundo de Raposo (2006) que apresentou como dissertação de mestrado, ao Programa de Pós-graduação em Educação da Universidade de Brasília, o estudo intitulado O Impacto do Sistema de Apoio da Universidade de Brasília na Aprendizagem de Universitários com Deficiência Visual. Objetivou compreender o impacto dos sistemas de apoio da Universidade de Brasília (UnB) na aprendizagem de universitários com deficiência visua; e o terceiro de Ferreira (2010) que apresentou como dissertação de mestrado, pelo Programa de Pós-graduação em 
Educação da Universidade Federal de Uberlândia - UFU, o estudo denominado Experiências vivenciadas por estudantes com Deficiência Visual em Instituições de Ensino Superior na Cidade de Uberlândia. Foi investigado experiências vivenciadas por estudantes com deficiência em IES de Uberlândia - MG, objetivando descrever a trajetória escolar dos sujeitos pesquisados, identificando os fatores que dificultam ou favorecem a inclusão no ambiente universitário.

No que diz respeito às políticas públicas de inclusão de estudantes com deficiência na Educação Superior, foram encontrados três estudos: um de Reis (2010) apresentado como dissertação de mestrado, pelo Programa de Pós-graduação em Educação pela Universidade Federal de Minas Gerais - UFMG, o estudo intitulado Política de inclusão escolar de pessoas com necessidades educacionais especiais no ensino superior e as universidades federais mineiras. Cujo o objetivo foi investigar o processo de organização e estruturação das políticas de inclusão de estudantes com necessidades educacionais especiais nas Universidades Federais Mineiras (UFM); outro de Miranda (2014) que defendeu como tese de doutorado, pelo Programa de Pós-graduação em Educação, da Faculdade de Filosofia e Ciências, da Universidade Estadual Paulista "Júlio de Mesquita Filho" da Unesp, campus Marília, a pesquisa intitulada Inclusão no ensino superior: das políticas públicas aos programas de atendimento e apoio às pessoas com necessidades educacionais especiais. Este estudo teve como finalidade conhecer o panorama atual dos programas e ações que as universidades públicas estaduais do Paraná instituíram para viabilizar a inclusão de estudantes com deficiência em seus contextos; o de Silveira (2015) que defendeu como tese de doutorado, pelo Programa de Pós-Graduação em Educação da Universidade do Vale do Itajaí - Univali, um estudo intitulado Política de inclusão no ensino superior na modalidade EaD nas universidades privadas, que analisou a política de inclusão no Ensino Superior na modalidade EAD, sua interpretação e aplicação no projeto pedagógico de três instituições privadas atuantes no Brasil. Vale ressaltar que esse foi o único estudo encontrado enfocando a Inclusão na Educação Superior na modalidade EaD.

No que diz respeito às possibilidades de avaliar e proporcionar acessibilidade no contexto de Inclusão na Educação Superior foram encontrados cinco estudos, sendo um de Ramalho (2012) que defendeu tese de doutorado, pelo Programa de Pós-graduação em Educação, da Universidade Estadual do Rio de Janeiro, UEFR, intitulada $A$ inclusão de estudantes com deficiência na UEPB: uma avaliação do programa de tutoria especial. A 
pesquisa realizada na Universidade Estadual da Paraíba (UEPB), nos cursos de Pedagogia, História, Filosofia, Comunicação Social, Serviço Social, Direito e Física, objetivou avaliar as contribuições do Programa de Tutoria nela existente; o de Santos (2012) que apresentou como dissertação de mestrado, pelo Programa de Pós-graduação em Educação, da Universidade Federal do Rio Grande do Norte - UFRN, o estudo intitulado Inclusão de estudantes com deficiência nas instituições de ensino superior da cidade do Natal/RN: análise das condições oferecidas no processo seletivo vestibular. A proposta do estudo foi investigar em que medida as IESs da cidade de Natal - RN estão seguindo recomendações da legislação brasileira, especificamente a do Aviso Circular no 277/96MEC/GM, no que se refere às condições oferecidas aos estudantes com deficiência para o processo seletivo vestibular.

Castilho (2012) defendeu como dissertação de Mestrado, pelo Programa de Pósgraduação em Psicologia, da Universidade Estadual de Maringá - UEM, a pesquisa denominada Caracterização das condições de acessibilidade previstas para o acadêmico com necessidades educacionais especiais nas Instituições Públicas de Ensino Superior do Estado do Paraná. Este estudo teve como propósito caracterizar as estratégias de acessibilidade para a permanência dos estudantes com NEE nas Universidades públicas Estaduais e Federais do Estado do Paraná; Saraiva (2015) que apresentou como dissertação de Mestrado ao Programa de Pós-graduação em Educação da Universidade Federal do Rio Grande do Norte - UFRN, o estudo denominado Núcleos de Acessibilidade e o atendimento de estudantes com necessidades educacionais especiais nas Universidades Federais do Nordeste Brasileiro. Sua pesquisa buscou analisar o trabalho desenvolvido pelos núcleos de acessibilidade constituídos nas universidades federais do nordeste brasileiro para atendimento aos estudantes com necessidades educacionais especiais; e por fim, Santana (2016) que apresentou como dissertação de Mestrado ao Programa de Pós-graduação em Educação da Universidade Federal do Mato Grosso do Sul - UFMS o estudo denominado Acesso e permanência na Educação Superior estratégias e ações da divisão de acessibilidade e ações afirmativas/DIAF na UFMS. Sua empreendeu em analisar a Divisão de Acessibilidade e Ações Afirmativas (DIAF), enquanto estratégia para garantir o acesso e permanência de estudantes de graduação com deficiência na Educação Superior na UFMS. 
Além destes estudos apresentados, foram encontrados mais 11 estudos sobre inclusão na Educação Superior em IES de vários estados do país, que seguem brevemente:

- Sasazawa (2005) apresentou como dissertação intitulada Ensino Superior e Educação Especial na Universidade Estadual de Maringá: algumas reflexões, pelo Programa de Pós-graduação em Educação da Universidade Estadual de Maringá - UEM. Nesta pesquisa verificou e avaliou o atendimento direcionado aos estudantes com necessidades especiais e a existência de algum serviço de apoio a eles na Universidade Estadual de Maringá (UEM), estado do Paraná.

- Chahini (2006) apresentou ao Programa de Pós-graduação em Educação da Universidade Federal do Maranhão - UFMA a dissertação intitulada Desafios do Acesso e da Permanência de Pessoas com Necessidades Educacionais Especiais nas Instituições de Educação Superior de São Luís - MA. A autora analisou os principais desafios a ser superados para que estudantes com deficiências visual, auditiva e física tivessem acesso, permanência e atendimento especializado nas IES de São Luís - MA.

- Pellegrini (2006) apresentou como dissertação de mestrado, ao Programa de Pósgraduação em Educação da Universidade Federal de Santa Maria - UFSM, o estudo denominado Ingresso, acesso e permanência de estudantes com necessidades educacionais especiais na Universidade Federal de Santa Maria - UFSM - RS. Objetivou investigar $O$ ingresso, acesso e permanência dos estudantes com necessidades educacionais especiais na Universidade Federal de Santa Maria - UFSM/RS.

- Perini (2006) apresentou ao Programa de Pós-graduação em Educação da Universidade Católica de Goiás - UCG, a dissertação intitulada de O processo de inclusão no ensino superior em Goiás: a visão dos excluídos. Tal estudo propunha desvelar o processo de inclusão escolar, no Ensino Superior, focalizando-se na percepção dos jovens deficientes.

- Drezza (2007) apresentou como dissertação de mestrado, ao Programa de Pósgraduação em Educação, da Universidade da Cidade de São Paulo - UNICID, estudo o qual chamou de Inclusão no Ensino Superior: relato de experiência sobre uma política de inclusão na Universidade Cidade de São Paulo. Objetivou estudar a inclusão dos estudantes com deficiência no ensino superior com base na análise das políticas internas e do trabalho do Centro de Apoio Acadêmico aos Deficientes da Universidade Cidade de São Paulo. 
- Alcoba (2008) defendeu como tese de seu doutorado, pelo Programa de Pósgraduação em Educação da Universidade Estadual de Campinas - Unicamp, o estudo intitulado Estranhos no ninho: a inclusão de estudantes com deficiência na Unicamp. $\mathrm{O}$ objetivo desse estudo era investigar como os professores da Unicamp encaravam as possibilidades de acesso e permanência dos estudantes com deficiência nos cursos superiores dessa instituição, para conhecer quais os recursos já disponíveis para construir um ambiente inclusivo nessa universidade e o que se apresentava como obstáculo à sua concretização.

- Viana (2010) apresentou como dissertação de mestrado, pelo Programa de PósGraduação em Educação da Universidade Federal de Alagoas - UFAL, o estudo intitulado O processo de inclusão de pessoas com deficiência nas instituições de ensino superior de Maceió. O propósito deste estudo foi analisar o processo de inclusão de pessoas com deficiência nos cursos de licenciatura de IES de Maceió. Foram entrevistados 14 acadêmicos com deficiência.

- Borges (2011) apresentou como dissertação mestrado pelo Programa de Educação da Faculdade de Ciências e Tecnologia da Universidade Estadual Paulista "Júlio de Mesquita Filho" (Unesp), campus Presidente Prudente, o estudo $A$ inclusão de estudantes com deficiência em cursos presenciais de graduação da Universidade de Juiz de Fora, cujo o objetivo foi investigar a realidade escolar de estudantes com deficiência que ingressaram em cursos presenciais da UFJF.

- Guimarães (2011) apresentou como dissertação de mestrado, pelo Programa de Pós-graduação em Educação pela Universidade Federal do Rio Grande do Norte, UFRN, o estudo denominado Ações inclusivas para permanência das pessoas com deficiência no ensino superior: um estudo em IES de Natal - RN. Sua pesquisa teve como objetivo identificar as ações inclusivas desenvolvidas pelas IES da cidade do Natal - RN para a permanência das pessoas com deficiência em cursos de graduação.

- Oliveira (2011) defendeu como tese de doutorado, pelo Programa de Pós-graduação em Educação Especial da Universidade Federal de São Carlos - UFSCar, Campus São Carlos, a pesquisa denominada Estudantes com deficiência no ensino superior: subsídios para a política de inclusão da Unimontes. Seu estudo teve como objetivo

\footnotetext{
[...] além de identificar quantos estudantes deficientes tiveram seu "ingresso", "acesso" pelo sistema de cotas, buscou também os números de quantos concluíra e ou estão cursando com o objetivo de conhecer sua "permanência" na Universidade" (OLIVEIRA, 2011, p. 114).
} 
- Piza (2011) defendeu como tese de doutorado, pelo Programa de Pós-graduação em Educação da Universidade Estadual Paulista Júlio de Mesquita Filho, Unesp - Marília, a pesquisa intitulada $O$ processo inclusivo em uma instituição particular de ensino superior do estado de São Paulo. Objetivando verificar como ocorria a inclusão de estudantes com deficiência nos cursos de graduação da Universidade Metodista de Piracicaba, Unimep.

Ressalta-se que foram encontrados apenas três estudos mais abrangentes sobre Inclusão na Educação Superior, realizados em nível Nacional, sendo um de Souza (2010) que apresentou a dissertação de mestrado, denominada Programa Incluir (2005-2009): uma iniciativa governamental de educação especial para a Educação Superior no Brasil, pelo Programa de Pós-graduação em Educação da Universidade Federal de Santa Catarina - UFSC. Nesse estudo analisou o Programa de Acessibilidade na Educação Superior (Incluir), por meio de cinco editais publicados pelo MEC entre os anos de 2005 e 2009, nas IES contempladas pelo Programa. Castro (2011) defendeu como tese de doutorado, pelo Programa de Pós-graduação em Educação Especial da Universidade Federal de São Carlos - UFSCar, campus São Carlos, a pesquisa intitulada Ingresso e permanência de estudantes com deficiência em universidades brasileiras. Sua pesquisa objetivou identificar as ações e iniciativas de universidades públicas brasileiras quanto ao ingresso e permanência de pessoas com deficiência, a fim de verificar as barreiras e os facilitadores encontrados por esses estudantes no cotidiano do ensino superior. E, Ciantelli (2015), que apresentou como dissertação de Mestrado ao Programa de Pós-graduação em Psicologia do Desenvolvimento e da Aprendizagem da Universidade Estadual Paulista Júlio de Mesquita Filho, Unesp - Bauru, a pesquisa intitulada Estudantes com Deficiência na Universidade: Contribuições da psicologia para as ações do Núcleo de Acessibilidade. Este estudo foi realizado na IFES e teve como propósito analisar as ações desenvolvidas pelos núcleos de acessibilidade, com ênfase para a atuação da psicologia em prol da participação de estudantes com deficiência na Educação Superior.

\section{Estudos sobre inclusão na Educação Superior que tem como foco: docentes, funcionários, estudantes}

Para compor esta categoria, foram identificados seis estudos, tendo como foco: docentes funcionários e estudantes. Cinco desses estudos eram dissertações (mestrado) e 2 teses (doutorado), descritos brevemente a seguir. 
Dentre esses sete estudos, cinco deles enfatizavam o ponto de vista dos docentes, sendo eles os estudos de Santos (2009), que apresentou como dissertação de mestrado apresentada ao Programa de Pós-graduação em Educação da Universidade Federal de Uberlândia - UFU, o estudo denominado Educação inclusiva no ensino superior: o docente universitário em foco. O estudo objetivou identificar as concepções de deficiência, de formação de professores e do processo de ensino-aprendizagem, que os docentes universitários possuem ante a questão da educação inclusiva, buscando perceber se tais concepções são adequadas ou não à prática inclusiva.

Sousa (2009) apresentou como dissertação de mestrado, ao Programa de Pósgraduação em Educação da Universidade Estadual do Rio de Janeiro - UERJ, o estudo intitulado Inclusão de Estudantes Deficientes Visuais na Universidade: focalizando professores e funcionários. Este estudo verificou as atitudes dos professores quanto à inclusão de estudantes com Deficiência Visual no Curso Superior (UEMG). Vale ressaltar que o estudo de Sousa (2009), além de ter como foco as atitudes dos professores, também salientou as atitudes dos demais funcionários da IES diante da Inclusão de estudantes com Deficiência Visual na Educação Superior.

Albino (2010), apresentou como dissertação de mestrado, pelo Programa de Pósgraduação em Educação pela Universidade Federal do Rio Grande do Norte, UFRN, o estudo intitulado Acesso e permanência na Universidade Federal do Rio Grande do Norte sob o ponto de vista do docente e do estudante com deficiência. A pesquisadora buscou analisar ações e práticas pedagógicas situando-se do ponto de vista de estudantes com deficiência e dos docentes, obtendo por eles dados sobre as condições de acesso e permanência oferecidas pela UFRN. Nogueira (2010) apresentou como dissertação de mestrado ao Programa de Pós-graduação em Educação da Universidade de Sorocaba Uniso, seu estudo intitulado Inclusão de deficientes no ensino superior: o trabalho docente frente ao processo de inclusão, que a autora investigou o trabalho docente frente à inclusão de estudantes com deficiência no ensino superior.

Chahini (2010) defendeu como tese de doutorado, pelo Programa de Educação da Universidade Estadual de Paulista - Unesp, campus Marília, o estudo denominado Atitudes Sociais e Opiniões de Professores e Estudantes da Universidade Federal do Maranhão em Relação à Inclusão de Estudantes com Deficiência na Educação Superior. A autora teve como objetivo geral analisar as atitudes sociais e opiniões de professores e estudantes da 
Universidade Federal do Maranhão - UFMA sobre a inclusão de estudantes com deficiência na Educação Superior.

Rossetto (2010) defendeu como tese de doutorado, pelo Programa de Pós-Graduação em Educação Especial pela Universidade Federal do Rio Grande do Sul - UFRS, o estudo nomeado como Sujeitos com Deficiência no Ensino Superior: vozes e significados. Essa pesquisa buscou compreender as singularidades da trajetória dos sujeitos com deficiência, identificando suas características e suas especificidades no contexto da Universidade Estadual do Oeste do Paraná - Unioeste.

Shimite (2017) apresentou como dissertação de mestrado ao Programa de Pósgraduação em Educação da Faculdade de Filosofia e Ciências da Universidade Estadual Paulista - UNESP o estudo intitulado Inclusão e educação tecnológica em foco: percepções de uma aluna com deficiência visual, de seus professores e seus colegas. A pesquisa teve como objetivo, descrever a formação profissional de uma aluna com deficiência visual em curso de Tecnologia em Alimentos, a partir da percepção da própria aluna, dos 22 professores do curso e dos 29 estudantes de sua sala de aula.

Observou-se que o estudo de Chahini (2010), além de apresentar as atitudes sociais e opiniões de professores no que abarca à inclusão na Educação Superior, também trouxe o ponto de vista dos estudantes com deficiência, assim como o estudo de Rossetto (2010) que buscou compreender a percepção dos estudantes, dando voz e significados a esta população, e; Shimite (2017) que por meio de um estudo de caso, apresentou a percepção da própria aluna com deficiência, seus professores e colegas.

\section{Estudos sobre Avaliação de Satisfação de Estudantes PAEE em relação a inclusão na Educação Superior}

E por fim, para compor essa categoria, foram encontrados dois estudos, que serão descritos mais detalhadamente, os quais dizem respeito à Avaliação de Satisfação dos estudantes com deficiência, os estudos de Guerreiro (2011) e Corrêa (2014).

Guerreiro (2011) defendeu como tese de doutorado, pelo Programa de Pós-graduação em Educação Especial da Universidade Federal de São Carlos - UFSCar, Campus São Carlos, a pesquisa intitulada Avaliação da satisfação do aluno com deficiência no Ensino Superior: estudo de caso. Seu estudo objetivou conhecer o nível de satisfação do aluno com deficiência quanto ao acesso e à permanência, mediante a construção de um instrumento, conhecido como Escala de Satisfação e Atitudes (ESA). Foi escolhida pela 
pesquisadora uma IES, a UFSCar, para identificar o perfil desse público e o nível de satisfação quanto às estruturas físicas e operacionais oferecidas, o nível de satisfação e atitudes perante os obstáculos, bem como os conhecimentos da legislação sobre acessibilidade. Dezoito estudantes participaram desta pesquisa sendo oito com deficiência visual, seis com deficiência física, três com deficiência auditiva e um com dificuldades de aprendizagem. Segundo Guerreiro (2011) este instrumento construído preconizava que sua aplicação adequada permite obter as seguintes informações:

(1) Identificação do aluno com deficiência ou com necessidades educacionais especiais;

(2) Caracterização do perfil dessa população;

(3) Conhecimento do nível de satisfação e de atitudes diante dos obstáculos dessa população.

(4) Mapeamento das barreiras arquitetônicas e urbanísticas pelos estudantes;

(5) Identificação das barreiras atitudinais apontadas pelo aluno (GUERREIRO, 2011, p. 193).

Por meio dos resultados obtidos com a aplicação da ESA, a autora afirmou que a mensuração do nível de satisfação do estudante com deficiência na educação superior é uma importante ferramenta para a gestão educacional, é viável e útil, no sentido de avaliar qual a direção que a universidade está tomando para garantir o acesso e permanência desses estudantes.

Corrêa (2014) defendeu a tese de doutorado, pelo Programa de Pós-graduação em Educação, da Faculdade de Filosofia e Ciências, da Universidade Estadual Paulista "Júlio de Mesquita Filho" - Unesp, campus Marília, intitulada Acessibilidade no Ensino Superior: Instrumento para avaliação, satisfação dos alunos com deficiência e percepção de coordenadores de cursos. Sua pesquisa buscou, por meio de três estudos, analisar as condições de acessibilidade e a satisfação dos alunos com deficiência em sete faculdades de uma Instituição de Ensino Superior do estado de São Paulo e a percepção dos coordenadores de cursos. Por meio dos resultados, o autor verificou que os coordenadores de cursos participantes estabeleceram boa convivência com os alunos com deficiência e, embora necessitem de preparo e formação específica para isso, relataram ações que influenciaram mais na permanência dos alunos com deficiência do que em seu acesso à Instituição de Educação Superior. Segundo a pesquisadora, a respeito dos Núcleos de Acessibilidade os dados indicaram o que faltava para atender as necessidades desses 
alunos e que esses núcleos também devem procurar se articular com os diferentes órgãos presentes na instituição.

Estudos acerca de instituições que venham implantando Núcleos de Acessibilidades, são necessários para verificar quais ações adotadas estão servindo como incentivo para outras IES.

\section{Estudo de revisão teórica sobre a inclusão na Educação Superior}

Esta categoria identificada é composta por um único estudo de revisão teórica, intitulado Um estudo de produções científicas: ingresso e permanência de universitários com deficiência, de Urban (2016), que foi apresentado como dissertação de Mestrado ao Programa de Pós-graduação em Educação Escolar da Faculdade de Ciências e Letras da Universidade Estadual Paulista Júlio de Mesquita Filho - Unesp, campus de Araraquara. A pesquisadora buscou analisar o acesso e a permanência no ensino superior de pessoas com deficiência, a partir de teses e dissertações defendidas nas universidades brasileiras. Por meio de uma pesquisa bibliográfica de cunho qualitativo e quantitativo, tendo como objeto de estudo 20 produções científicas (15 dissertações e cinco teses), que apresentaram o perfil dos estudantes presentes nesses estudos; os cursos de graduação em diversas áreas do conhecimento, as instituições frequentadas; as adaptações de acesso realizadas durante o vestibular; as ações de permanência e acessibilidade. Também foram apresentadas as barreiras arquitetônicas, pedagógicas, comunicacionais e atitudinais, encontradas nas IES. A pesquisadora concluiu que os estudantes com deficiência estão nas IES e necessitam de apoio durante o acesso e a permanência e que têm sido realizadas ações pelas diferentes esferas das IES, porém esses estudantes ainda têm encontrado barreiras para sua efetiva permanência. A respeito dos Núcleos de Acessibilidade a autora considerou que são importantes para a formação desses estudantes, pois além de disponibilizar recursos materiais e pessoais, orientação aos professores, é um local de referência à inclusão dentro da IES.

"Ao trazer esses locais, nota-se a necessidade de que todas as IES tenham esse para a fomentação de ações inclusivas, bem como garantam meios de suprir a necessidade desse educando durante sua permanência" (URBAN, 2016, p. 101).

Isto posto, é importante frisar que esse tipo de estudo é emergente e necessário para melhor compreensão do caminho percorrido e do cenário atual de inclusão na Educação Superior. 


\section{Estudo de intervenção para inclusão de estudantes com Deficiência na Educação} Superior

Nesta categoria, um único estudo de intervenção para a inclusão de estudantes com Deficiência Intelectual na Educação Superior foi encontrado. Lopes (2016) defendeu como tese de doutorado, pelo Programa de Pós-graduação em Educação Especial da Universidade Federal de São Carlos - UFSCar, Campus São Carlos, a pesquisa intitulada Programa de Transição para a vida adulta de jovens com deficiência intelectual em ambiente universitário. Seu estudo objetivou analisar os efeitos de um Programa de Transição para a Vida Adulta no Ambiente Universitário que tem como finalidade propiciar experiências de aprendizagem para a vida dos jovens com DI. Participaram da pesquisa: quatro estudantes com DI, nove professores de disciplinas específicas e 18 professores de disciplinas regulares do Centro Universitário; e trinta e dois tutores, estudantes da Educação Superior. Lopes (2016, p. 8) constatou que

[...] o Planejamento Centrado no Aluno associado às estratégias utilizadas pelos professores e apoio dos tutores na realização das atividades acadêmicas e sociais também contribuíram para o desenvolvimento e independência de cada participante.

Esse estudo apresentou possibilidades de estudantes com DI participarem em programas no ambiente universitário com resultados satisfatórios, podendo também ser considerado emergente, uma vez que aponta caminhos para a inclusão na Educação Superior.

\section{Estudo sobre Ações do Núcleo de Acessibilidade na EAD em Instituição de Educação Superior Privada}

E, para finalizar, o único estudo que aborda a inclusão na Educação Superior de um IES privada e as ações do Núcleo de Acessibilidade na modalidade EaD. Fantacini (2017) defendeu como tese de doutorado, pelo Programa de Pós-graduação em Educação Especial da Universidade Federal de São Carlos - UFSCar, Campus São Carlos, a pesquisa intitulada Ações do Núcleo de Acessibilidade na EaD de uma Instituição de Educação Superior privada e a Satisfação dos estudantes com deficiência. O objetivo foi descrever e analisar como vinham ocorrendo as ações deste Núcleo de Acessibilidade nos cursos de graduação da modalidade de Educação a Distância de uma Instituição de 
Educação Superior privada e avaliar a satisfação dos estudantes com deficiência, em relação a tais ações.

O estudo foi realizado no Núcleo de Acessibilidade de uma IES privada. Foi realizada uma pesquisa exploratória e descritiva, de abordagem quantitativa e qualitativa. Nesta pesquisa participaram as professoras que compõem o Núcleo de Acessibilidade e 21 estudantes identificados público-alvo da Educação Especial que se autodeclararam e solicitaram apoio ao Núcleo de Acessibilidade. Os resultados revelaram que os membros desse Núcleo de Acessibilidade têm formação adequada para atuar nessa função; com mapeamento do público-alvo da Educação Especial, foi possível verificar que a instituição tinha, em 2016, 137 estudantes público-alvo da Educação Especial incluídos em seus cursos de Educação a Distância, destes, somente 26 estudantes se autodeclararam e solicitaram algum tipo de suporte do NA. Ao final da pesquisa, por meio da aplicação da Escala de Satisfação e Atitudes - ESA, foi possível conhecer o nível de satisfação e de atitudes dessa população no que tange às ações do NA, além de possibilitar a identificação e apontar alguns caminhos para a superação das barreiras estruturais, operacionais, psicoafetivas e atitudinais diante de obstáculos. Fantacini (2017) concluiu que a mensuração do nível de satisfação dessa população é necessária e pode contribuir para a construção de contextos inclusivos na Educação a Distância desta instituição e, este estudo pode, por sua vez, constituir-se em importante ferramenta para o NA, no sentido de ajudar a desenvolver ações que acompanhem e monitorem as ações implementadas, para a efetivação e a garantia da inclusão na Educação Superior a Distância desta instituição, dado que poderá trazer contribuições para outras instituições.

\section{Discussão}

Em relação ao número de produções, evidenciou-se 39 estudos, sendo 26 dissertações (mestrado) e apenas 13 teses (doutorado). Tal diferença pode ser justificada pelo menor número de programas de doutorado no país e também por demandar mais tempo para conclusão das pesquisas em relação às pesquisas de mestrado (BUENO, 2008).

O foco da maioria dos estudos apresentados aponta para a preocupação com o estudante público-alvo da Educação Especial na Educação Superior, dado este que pode nos indicar que, embora o acesso seja garantido, há a necessidade da IES se preparar para acolher e garantir a permanência deste estudante, que até pouco tempo era excluído dessa 
modalidade de ensino. Isso pode ser confirmado com o número de estudos que começam a se dedicar a temas como: acesso/ingresso, permanência, núcleos de acessibilidade, atendimento educacional especializado, sucesso escolar, dentre outros (BRITO; ZEPPONE, 2013).

Pode-se verificar que as pesquisas sobre inclusão na Educação Superior tiveram maior ênfase a partir do ano de 2005, nota-se também que nos últimos anos, houve um crescimento significativo, em número de pesquisas, sobretudo a partir de 2010 , e tal fato pode ser em decorrência da Política Nacional de Educação Especial na Perspectiva da Educação Inclusiva (BRASIL, 2008). Entretanto, somente a partir de 2014, é que surgiu a presença do descritor núcleo de acessibilidade na educação superior, mais precisamente nas pesquisas de Castro (2010), Miranda (2014) e Corrêa (2014), Ciantelli (2015), Saraiva (2015), Silveira (2015), Urban (2016) e Fantacini (2017).

Também se merece destacar que, diante das pesquisas de teses e dissertações defendidas no Brasil, foi encontrado, neste banco, apenas um estudo de revisão teórica sobre inclusão na Educação Superior (URBAN, 2016); um estudo de intervenção para a inclusão de estudantes com deficiência na Educação Superior (LOPES, 2016); e apenas um estudo (FANTACINI, 2017) que trata da implementação de Núcleos de Acessibilidade na Educação Superior de uma IES privada, na modalidade de Educação a Distância (EaD), que revela a existência de algumas ações de acesso e permanência do PAEE na Educação Superior privada, relacionadas a implementação de Núcleos de Acessibilidade na EaD.

\section{Considerações Finais}

As políticas de inclusão na Educação Superior asseguram efetiva participação do público-alvo da Educação Especial. Todavia, o seu aperfeiçoamento é constante por meio de alterações e/ou surgimento de novos marcos regulatórios.

Não obstante, é notável que a inclusão na Educação Superior seja recente e que demanda aprofundamento e estudos específicos relativos à sua existência. Cabe ressaltar ainda, que as instituições de Educação Superior necessitam aperfeiçoar os seus processos de atendimento e acessibilidade, considerando o Núcleo de Acessibilidade e demais recursos. Isto é crucial para que o estudante permaneça e alcance sucesso em sua aprendizagem.

Nesta perspectiva, a presente revisão sistemática apresentou o levantamento de teses e dissertações envoltas da temática do Núcleo de Acessibilidade na Educação 
Superior para a Educação a Distância de 2005 a 2018. Dado que ao realizar as buscas que configurassem o objeto deste estudo foi essencial alterar os descritores que atendessem ao objetivo definido.

Percebe-se que a maioria dos estudos é relacionada à inclusão na Educação Superior $\mathrm{EaD}$, contudo a especificidade de Núcleo de Acessibilidade para a Educação Superior na Educação a Distância foi atingida somente num único estudo.

E, por fim, a inclusão da Educação Superior, por se tratar de uma área ainda pouco explorada no panorama nacional, sugere-se que outras pesquisas sobre esta temática sejam realizadas.

\section{Referências}

ALBINO, Ivone Braga. Acesso e permanência na Universidade Federal do Rio Grande do Norte sob o ponto de vista do docente e do estudante com deficiência. 2010. 205f. Dissertação (Mestrado em Educação) - Universidade Federal do Rio Grande do Norte (UFRN), Natal, 2010.

ALCOBA, Susie de Araújo Campos. Estranhos no ninho: a inclusão de estudantes com deficiência na Unicamp. 2008. 140f. Tese (Doutorado em Educação) -Universidade Estadual de Campinas (Unicamp), Campinas, 2008.

ANSAY, Noemi Nascimento. A trajetória escolar de estudantes surdos e a sua relação com a inclusão no ensino superior. 2009. 133f. Dissertação (Mestrado em Educação) Universidade Federal do Paraná (UFPR), Curitiba, 2009.

BDTD. Biblioteca Digital Brasileira de Teses e Dissertações (BDTD). Disponível em: http://bdtd.ibict.br/pt/. Acesso em: 20 jan. 2017.

BORGES, Maria Aparecida. A inclusão de estudantes com deficiência em cursos presenciais de graduação da Universidade de Juiz de Fora. 2011. 142f. Dissertação (Mestrado em educação) - Universidade Estadual Paulista Júlio de Mesquita Filho (Unesp), Presidente Prudente, 2011.

BRASIL. Decreto ํㅜ 9.034, de 20 de abril de 2017. Altera o Decreto $\mathrm{n} \cong 7.824$, de 11 de outubro de 2012, que regulamenta a Lei $\mathrm{n} \circ 12.711$, de 29 de agosto de 2012, que dispõe sobre o ingresso nas universidades federais e nas instituições federais de ensino técnico de nível médio. Diário Oficial [da] República Federativa do Brasil, Brasília, 20 abr. 2012 Disponível em: http://www.planalto.gov.br/ccivil_03/_Ato20152018/2017/Decreto/D9034.htm. Acesso em: 02 jun. 2018.

BRASIL. Lei no 13.409 , de 28 de dezembro de 2016. Altera a Lei no 12.711 , de 29 de agosto de 2012. Para dispor sobre a reserva de vagas para pessoas com deficiência nos cursos técnico de nível médio e superior das instituições federais de ensino. Diário Oficial [da] República Federativa do Brasil, Brasília, 28 dez. 2016. Disponível 
em: http://www.planalto.gov.br/ccivil_03/_Ato2015-2018/2016/Lei/L13409.htm. Acesso em: 06 jun. 2018.

BRASIL. Lei no 12.711, de 29 de agosto de 2012. Dispõe sobre o ingresso nas universidades federais e nas instituições federais de ensino técnico de nível médio e dá outras providências. Diário Oficial [da] República Federativa do Brasil, Brasília, 29 ago. 2012. Disponível em: http://www.planalto.gov.br/ccivil_03/_ato20112014/2012/lei/l12711.htm. Acesso em: 02 jun. 2018.

BRASIL. Ministério da Educação - MEC. Aviso Curricular n. 277, de 8 de maio de 1996. Brasília, 8 maio 1996. Disponível em: http://portal.mec.gov. br/seesp/arquivos/pdf/aviso277.pdf. Acesso em: 20 jan. 2018.

BRASIL. Ministério da Educação - MEC. Secretaria da Educação Especial. Política nacional de Educação Especial na perspectiva da educação inclusiva. Brasília: MEC/SEESP, $2008 . \quad$ Disponível em: http://portal.mec.gov.br/arquivos/pdf/politicaeducespecial.pd>. Acesso em: 20 jan. 2018. BRASIL. Ministério da Educação. Secretaria de Educação Especial. Política Nacional de Educação Especial. Brasília: MEC/SEESP, 1994.

BRASIL. Decreto no 7.611, de 17 de novembro 2011. Dispõe sobre a educação especial, o atendimento educacional especializado e dá outras providências. Diário Oficial [da] República Federativa do Brasil, Brasília, 17 nov. 2011. Disponível em: http://www.planalto.gov.br/ccivil_03/_Ato2011-2014/2011/Decreto/D7611.htm. Acesso em: 20 jan. 2018.

BRASIL. Programa Incluir. Documento orientador. Programa Incluir - Acessibilidade na Educação Superior Secadi/SESu (2013a). Disponível em: http://portal.mec.gov.br/index.php?option=com_docman\&view=download\&alias=13292doc-ori-progincl\&category_slug=junho-2013-pdf\&ltemid=30192. Acesso em: 20 jan. 2018.

BRASIL. Referenciais de Acessibilidade na Educação Superior e a Avaliação in loco do Sistema Nacional de Avaliação da Educação Superior (Sinaes). 2013b. Disponível em: http://www.ampesc.org.br/_arquivos/download/1382550379.pdf. Acesso em: 20 jan. 2018.

BRASIL. Referenciais de Qualidade para Educação Superior a Distância. 2007. Disponível em:http://portal.mec.gov.br/seed/arquivos/pdf/legislacao/refead1.pdf. Acesso em: 20 jan. 2018.

BRASIL. Lei no 13.146, de 6 de julho de 2015. Institui a Lei Brasileira de Inclusão da Pessoa com Deficiência (Estatuto da Pessoa com deficiência). Diário Oficial [da] República Federativa do Brasil, Brasília, 6 jul. 2015. Disponível em: http://www.planalto.gov.br/ccivil_03/_ato2015-2018/2015/lei//13146.htm. Acesso em: 02 jun. de 2018.

BRASIL. Instituto Nacional de Estudos e Pesquisas Educacionais Anísio Teixeira - Inep. Instrumento de Avaliação de Cursos de Graduação 
Presencial e a distância. 2016. Disponível em: http://cpa.ufsc.br/files/2017/02/Instrumento-Curso-2016.pdf. Acesso em: 20 jan. 2018.

BRASIL. Lei no $=13.409$, de 28 de dezembro de 2016. Altera a Lei no 12.711 , de 29 de agosto de 2012. Para dispor sobre a reserva de vagas para pessoas com deficiência nos cursos técnico de nível médio e superior das instituições federais de ensino. Diário Oficial [da] República Federativa do Brasil, Brasília, 28 dez. 2016. Disponível em: http://www.planalto.gov.br/ccivil_03/_Ato2015-2018/2016/Lei/L13409.htm. Acesso em: 06 jun. 2018.

BRITO, Jéssica de; ZEPPONE, Rosimeire Maria Orlando. Mapeamento de teses e dissertações sobre a inclusão de pessoas com deficiência no ensino superior no Brasil. In: CONGRESSO BRASILEIRO MULTIDISCIPLINAR DE EDUCAÇÃO ESPECIAL, VIII., Londrina. Anais... Londrina: Associação Brasileira de Pesquisadores em Educação Especial, 2013.

BUENO, José Geraldo Silveira. Deficiência e ensino superior: balanço das dissertações e teses brasileiras (1987/2006). In: SEMINÁRIO CAPIXABA DE EDUCAÇÃO INCLUSSIVA, XI., 2008, Vitória/ES. Anais... Vitória: Universidade Federal do Espírito Santo, 2008. p. 100112.

CASTILHO, Annamaria Coelho de. Caracterização das condições de acessibilidade previstas para 0 acadêmico com necessidades educacionais especiais nas instituições públicas de Ensino Superior do Estado do Paraná. 2012. 109f. Dissertação (Mestrado em Psicologia) - Universidade Estadual de Maringá, Maringá, 2012.

CASTRO, Sabrina Fernandes. Ingresso e permanência de estudantes com deficiência em universidades públicas brasileiras. 2011. 278f. Tese (Doutorado em Educação Especial) - Universidade Federal de São Carlos (UFSCar), São Carlos, 2011.

CHAHINI, Thelma Helena Costa. Os desafios do acesso e da permanência de pessoas com necessidades educacionais especiais nas instituições de educação superior de São Luís - MA. 2006. 203f. Dissertação (Mestrado em Educação) - Universidade Federal do Maranhão (UFMA), São Luís, 2006.

CHAHINI, Thelma Helena Costa. Atitudes sociais e opiniões de professores e estudantes da Universidade Federal do Maranhão em relação à inclusão de estudantes com deficiência na Educação Superior. 2010. 131f. Tese (Doutorado em Educação) - Universidade Estadual Paulista (Unesp), Marília, 2010.

CIANTELLI, Ana Paula Camilo. Estudantes com deficiência na universidade: contribuições da psicologia para as ações do núcleo de acessibilidade. 2015. $183 f$. Dissertação (Mestrado em Psicologia do Desenvolvimento e da Aprendizagem) Universidade Estadual Paulista (Unesp), Faculdade de Ciências, Bauru, 2015.

CORRÊA, Priscila Moreira. Acessibilidade no ensino superior: instrumento para avaliação, satisfação dos alunos com deficiência e percepção de coordenadores de cursos. 
2014. 281 f. Tese (Doutorado em Educação) - Universidade Estadual Paulista (Unesp), Faculdade de Filosofia e Ciências de Marília, Marília, 2014.

DREZZA, Eduardo José. Inclusão no Ensino Superior: relato de experiência sobre uma política de inclusão na Universidade Cidade de São Paulo. 2007. 75f. Dissertação (Mestrado em Educação) - Universidade da Cidade de São Paulo (Unicid), São Paulo, 2007.

FANTACINI, Renata Andrea Fernandes. Ações do Núcleo de Acessibilidade na EaD de uma instituição de Educação Superior privada e a satisfação dos estudantes com deficiência. 2017. 192f. Tese (Doutorado em Educação Especial) - Programa de PósGraduação em Educação Especial, Universidade Federal de São Carlos, São Carlos, 2017.

FERREIRA, Lavine Rocha Cardoso. Experiências vivenciadas por estudantes com Deficiência Visual em Instituições de Ensino Superior na cidade de Uberlândia/MG. 2010. 141f. Dissertação (Mestrado em Educação) -Universidade Federal de Uberlândia (UFU), Uberlândia, 2010.

FORTES, Vanessa Gosson Gadelha de Freitas. A inclusão da pessoa com deficiência visual na UFRN: a percepção dos acadêmicos. 2005. 240f. Dissertação (Mestrado em Educação) - Universidade Federal do Rio Grande do Norte (UFRN), Natal, 2005.

GUERREIRO, Elaine Maria Bessa Rebello. Avaliação da satisfação do aluno com deficiência no Ensino Superior: Estudo de caso da USFCAR. 2011. 229f. Tese (Doutorado em Educação Especial) - Universidade Federal de São Carlos (UFSCar), São Carlos, 2011.

GUIMARÃES, Clarisse Ferreira. Ações inclusivas para permanência das pessoas com deficiência no ensino superior: um estudo em IES de Natal - RN. 2011. 131f. Dissertação (Mestrado em Educação) - Universidade Federal do Rio Grande do Norte (UFRN), Natal, 2011.

LOPES, B. J. S. Programa de Transição para a vida adulta de jovens com deficiência intelectual em ambiente universitário. 2016. 246f. Tese (Doutorado em Educação Especial). Programa de Pós-Graduação em Educação Especial. Universidade Federal de São Carlos (UFSCar), São Carlos, 2016.

MIRANDA, Wagner Tadeu Sorace. Inclusão no ensino superior: das políticas públicas aos programas de atendimento e apoio às pessoas com necessidades educacionais especiais. 2014. 183f. Tese (Doutorado em Educação) - Faculdade de Filosofia e Ciências, Universidade Estadual Paulista (Unesp), Marília, 2014.

NOGUEIRA, Lilian de Fátima Zanoni. Inclusão de deficientes no ensino superior: o trabalho docente frente ao processo de inclusão. 2010. 91f. Dissertação (Mestrado em Educação) - Universidade de Sorocaba (Uniso), Sorocaba, 2010. 
OLIVEIRA, Antonia Soares Silveira e. Estudantes com deficiência no ensino superior: subsídios para a política de inclusão da UNIMONTES. 2011. 182f. Tese (Doutorado em Educação) - Universidade Federal de São Carlos (UFSCar), São Carlos, 2011.

PELLEGRINI, Cleonice Machado de. Ingresso, acesso e permanência de estudantes com necessidades educacionais especiais na Universidade Federal de Santa Maria UFSM - RS. 2006. 196f. Dissertação (Mestrado em Educação) - Universidade Federal de Santa Maria (UFSM), Santa Maria, 2006.

PERINI, Thelma Iris. O processo de inclusão no Ensino Superior em Goiás: a visão dos excluídos. 2006. 121f. Dissertação (Mestrado em Educação) - Universidade Católica de Goiás, Goiânia, 2006.

PIZA, Maria Helena Machado. O processo inclusivo em uma instituição particular de ensino superior do estado de São Paulo. 2011. 110f. Tese (Doutorado em Educação) Universidade Estadual Paulista Júlio de Mesquita Filho (Unesp), Marília, 2011.

RAMALHO, Marilda Noalda. A inclusão de estudantes com deficiência na UEPB: uma avaliação do programa de tutoria especial. 2012. 174f. Tese (Doutorado em Educação) Universidade do Estado do Rio de Janeiro (UERJ), Rio de Janeiro, 2012.

RAPOSO, Patrícia Neves. O impacto do sistema de apoio da Universidade de Brasília na aprendizagem de universitários com Deficiência Visual. 2006. 164f. Dissertação (Mestrado em Educação) - Universidade de Brasília (UNB), Brasília, 2006.

REIS, Nilvania Maria de Melo. Política de inclusão escolar de pessoas com necessidades educacionais especiais no ensino superior $e$ as universidades federais mineiras. 2010. 188f. Dissertação (Mestrado em Educação) - Universidade Federal de Minas Gerais (UFMG), Belo Horizonte, 2010.

ROSSETTO, Elisabeth. Sujeitos com Deficiência no Ensino Superior: vozes e significados. 2010. 234f. Tese (Doutorado em Educação) - Universidade Federal do Rio Grande do Sul (UFRGS), Porto Alegre, 2010.

SAMPIERI, Roberto Hernandez; COLLADO, Carlos Fernandez; LUCIO, Maria del Pilar Baptista. Metodologia de pesquisa. Tradução de Daisy Vaz de Moraes. Revisão técnica de Ana Gracinda Queluz Garcia, Dirceu da Silva, Marcos Júlio. 5. ed. Porto Alegre: Penso, 2013.

SANTANA, Leila Lima de Souza. Acesso e permanência na Educação Superior estratégias e ações da divisão de acessibilidade e ações afirmativas DIAF na UFMS. 2016. 156f. Dissertação (Mestrado em Educação) - Universidade Federal de Mato Grosso do Sul (UFMS). Campo Grande, MS, 2016.

SANTOS, Amanda Fernandes. Educação inclusiva no ensino superior: o docente universitário em foco. 2009. 163f. Dissertação (Mestrado em Educação) - Universidade Federal de Uberlândia (UFU), Uberlândia, 2009. 
SANTOS, Andreza Souza. Inclusão de estudantes com deficiência nas instituições de ensino superior da cidade do Natal/RN: análise das condições oferecidas no processo seletivo vestibular. 2012. 140 f. Dissertação (Mestrado em Educação) - Universidade do Rio Grande do Norte (UFRN), 2012.

SARAIVA, Luzia Livia Oliveira. Núcleos de acessibilidade e o atendimento de estudantes com necessidade educacionais especiais nas universidades federais no nordeste brasileiro. 2015. 192f. Dissertação (Mestrado em Educação) - Universidade Federal do Rio Grande do Norte (UFRN), Natal, 2015.

SASAZAWA, Fabiana Harumi. Ensino Superior e Educação Especial na Universidade Estadual de Maringá: algumas reflexões. 2005. 114f. Dissertação (Mestrado em Educação) - Universidade Estadual de Maringá (UEM), Maringá, 2005.

SILVA, Elza Maria do Socorro da. O processo de inclusão: objetivação e ancoragem do primeiro aluno surdo numa instituição de ensino superior. 2017. 140f. Dissertação (Mestrado em Educação) - Pontifica Universidade Católica de Goiás, Goiania - GO, 2017.

SILVEIRA, Tatiana dos Santos da. Política de Inclusão no Ensino Superior na modalidade EaD nas universidades privadas. 2015. 139f. Tese (Doutorado em Educação) - Universidade do Vale do Itajaí (Univali), Santa Catarina, 2015.

SHIMITE, Amabriane da Silva Oliveira. Inclusão e educação tecnológica em foco: percepções de uma aluna com deficiência visual, de seus professores e de seus colegas. 2017. 107f. Dissertação (Mestrado em Educação) - Universidade Estadual Paulista (Unesp), Faculdade de Filosofia e Ciências, Marília, 2017.

SOUSA, Saulo Sebastião de. Inclusão de estudantes deficientes visuais na universidade: focalizando professores e funcionários. 2009. 209f. Dissertação (Mestrado em Educação) - Universidade do Estado do Rio de Janeiro (UERJ), Rio de Janeiro, 2009.

SOUZA, Bianca Costa Silva de. Programa INCLUIR (2005 -2009): uma iniciativa governamental de educação especial para a educação superior no Brasil. 2010. 179f. Dissertação (Mestrado em Educação) - Universidade Federal de Santa Catarina (UFSC). Florianópolis, SC, 2010.

URBAN, Ana Lídia Penteado. Um estudo de produções científicas: ingresso e permanência de Universitários com deficiência. 2016. 130f. Dissertação (Mestrado em Educação) - Universidade Estadual Paulista "Júlio de Mesquita Filho" (Unesp), Faculdade de Ciências e Letras, Araraquara, 2016.

VIANA, Marcia Rafaella Graciliano dos Santos. O processo de inclusão de pessoas com deficiência nas instituições de ensino superior de Maceió. 2010. 133f. Dissertação (Mestrado em Educação) - Universidade Federal de Alagoas (UFAL), Maceió, 2010.

\section{Correspondência}

Renata Andrea Fernandes Fantacini - Claretiano, Centro Universitário R. Dom 
http://dx.doi.org/10.5902/1984686X36305

Bôsco, 466 - Bairro Castelo. CEP: 14300-000. Batatais, São Paulo, Brasil.

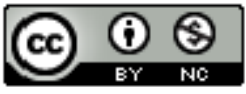

This work is licensed under a Creative Commons Attribution-NonCommercial 4.0 International (CC BY-NC 4.0) 